\title{
Video-assisted thoracic surgery right lower lobe common basal segmentectomy (S7-S8-S9-S10)
}

\author{
Andres Obeso ${ }^{1}$, Carlos Galvez ${ }^{2}$, Eduardo Rivo ${ }^{1}$, Jorge Quiroga ${ }^{1}$, Jose Maria Garcia Prim ${ }^{1}$ \\ ${ }^{1}$ Thoracic Surgery Department, Hospital Clínico Universitario de Santiago de Compostela, Santiago de Compostela, Spain; ${ }^{2}$ Thoracic Surgery \\ Department, Hospital General Universitario de Alicante, Alicante, Spain \\ Correspondence to: Andres Obeso. Thoracic Surgery Department, Hospital Clínico Universitario de Santiago de Compostela, Rua Choupana s/n, ZYP \\ 15706, Santiago de Compostela (A Coruña), Spain. Email: andresobca@hotmail.com.
}

\begin{abstract}
Video-assisted thoracic surgery (VATS) anatomic segmentectomy is becoming more and more frequent surgical procedure over time, specially due to the increasing use and diffusion of minimally invasive techniques. Single or combined basal segmentectomies are usually more technically complex than other types of segmentectomies because of the deeper intraparenchymal localization of the hilar structures, more frequent anatomical variations, and more challenging identification of the intersegmental planes. The right basilar segmentectomy is a multisegmentectomy which includes the medial basal (S7), anterior basal (S8), lateral basal (S9) and posterior basal (S10). These segments can be removed together since they depend from a single bronchial trunk. The bronchovascular elements (V6, A6, B6) of the superior segment (S6) of the right lower lobe must be preserved. The preoperative contrast-enhanced high-resolution computed tomography scan must be carefully reviewed in order to plan the surgical procedure. It is essential to identify preoperatively possible anatomical variants and infrequent anatomical patterns so as to avoid cutting wrong structures during the surgery. The availability of new softwares allow to obtain precise three dimensional models of the airway and pulmonary vessels. The aim of this manuscript is to describe the operative steps, tips, pitfalls and caveats of VATS right lower lobe common basal segmentectomy (S7-S8-S9-S10).
\end{abstract}

Keywords: Segmentectomy; sublobar; video-assisted thoracic surgery (VATS)

Received: 02 June 2021; Accepted: 19 July 2021; Published: 20 October 2021.

doi: 10.21037 /jovs-21-32

View this article at: https://dx.doi.org/10.21037/jovs-21-32

\section{Introduction}

Video-assisted thoracic surgery (VATS) anatomic segmentectomy is becoming more and more frequent surgical procedure over time, specially due to the increasing use and diffusion of minimally invasive techniques. Traditionally, this lung-sparing technique was preferred only for patients with pulmonary metastases (1-3) or patients with non-small cell lung cancer (NSCLC) and limited cardiopulmonary reserve or multiple comorbidities (4-6), as long as wedge resection is not possible. Recently, a phase III randomized control trial (JCOG0802/WJOG4607L) (7) demonstrated the benefit of segmentectomy in comparison with lobectomy revealing statistically significant differences respect to overall survival. This study concluded that segmentectomy should be the standard surgical procedure instead of lobectomy for patients with small-sized $(<2 \mathrm{~cm}$, CTR $>0.5$ ) peripheral c-stage IA NSCLC.

Single or combined basal segmentectomies are usually more technically complex than other types of segmentectomies because of the deeper intraparenchymal localization of the hilar structures, more frequent anatomical variations, and more challenging identification of the intersegmental planes. The aim of this manuscript is to describe the operative steps, tips, pitfalls and caveats of VATS right lower lobe common basal segmentectomy (S7S8-S9-S10). 
Table 1 Anatomical patterns and possible variants of the right basilar segments

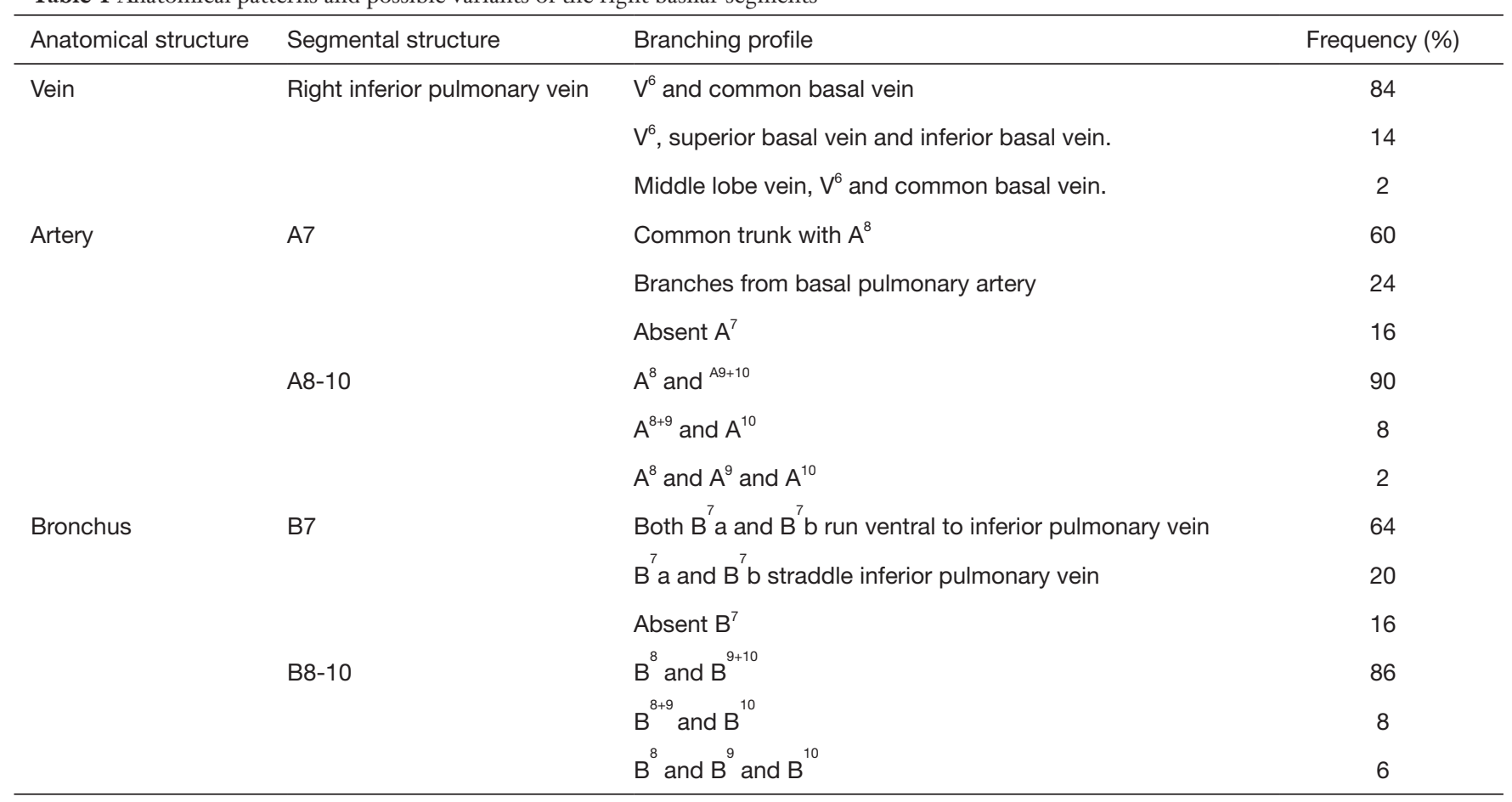

\section{Anatomical landmarks}

A thorough knowledge of the vascular and bronchial hiliar structures and segmental and subsegmental branches is essential before performing a segmentectomy. Table 1 shows the most frequent anatomical patterns and possible variants of the right basilar segments (8).

\section{Preoperative planning}

Contrast-enhanced high-resolution computed tomography (HRCT) scan must carefully reviewed preoperatively. First of all, the identification of the pulmonary segment where the target lesion is located should be determined based on its relationship with the segmental bronchus. In this specific segmentectomy, the pulmonary nodule must be located in the right common basal pyramid below the superior segmental bronchus $\left(\mathrm{B}^{6}\right)$.

Then, specific segmental vessels and bronchi as well as positional relationship of these segmental structures must be analyzed to design an appropriate surgical resection. Additionally it is essential to identify preoperatively possible anatomical variants and infrequent anatomical patterns in order to avoid cutting wrong structures during the surgery. Recently, the design of state-of-art software allows to obtain precise three dimensional (3D) models of the airway and pulmonary vessels. The application of these three dimensional computed tomography bronchography and angiography (3D-CTBA) programs clearly identify pulmonary segmental and subsegmental structures, avoids intraoperative accidental injury, shortens the operation time and improves the safety of VATS segmentectomy (9).

\section{Operative steps}

\section{Anesthesia management}

General anesthesia is induced and endotracheal intubation is performed using a double lumen tube. The patient is monitored by electrocardiography, pulse oximetry, capnography and bispectral Index (BIS). An intraarterial catheter is placed for hemodynamic control. However, central venous and pulmonary artery catheterization are not routinely used. Indwelling urinary catheter is usually necessary to monitor urinary output.

\section{Patient positioning}

The patient is placed in a standard left lateral decubitus position with arms flexed and stretched toward the head 
on appropriate supports. An axillary roll is placed in order to raise up the chest and open the intercostal spaces. Once the patient is correctly positioned, the skin is cleaned up with a chlorhexidine-based solution and draping is prepared in the usual manner. A prophylactic dose of Cefazolin is administered.

\section{Working incision}

In this case, the pleural cavity was approached by performing uniportal technique through the fifth intercostal space at the level of the anterior axillary line. If biportal technique is preferred, an additional port $(1 \mathrm{~cm})$ is placed in the eighth intercostal space at the level of the posterior axillary line. A flexible Alexis ${ }^{\mathrm{TM}}$ soft tissue wound protector (Applied Medical, Inc., Rancho Santa Margarita, CA, USA) is placed in the port rather than using a rib-spreading retractor decreasing postoperative pain. The entire procedure is performed under video-assisted visualization using a high definition 30-degree thoracoscopic camera. Before starting the surgical resection, criteria for nonresectability must be ruled out.

Note: The number of ports basically depends on the surgeon preferences. Biportal technique is also a suitable approach especially for anatomical segmentectomies. This biportal approach has several benefits. First we can put a grasper into the pleural cavity through the camera port improving the exposure and traction of the pertinent pulmonary segments. Additionally, this maneuver decrease the number of instruments through the utility port providing more comfortability to the surgeon. Second, and even more important, we can switch both the camera and the staplers in two different ports. It allows us to view the hiliar structures from different perspectives. Furthermore, we can insert the staplers from different angles decreasing the tension over the subsegmentary vessels which are specially fragile.

\section{Pulmonary nodule identification}

Visual or digital palpation and localization of the target tumor is recommended in order to confirm intraoperatively the planned segmentectomy. The width of the basal pyramid makes this decision easier than in other types of segmentectomies. The pulmonary nodule should be located far away from the intersegmental line with S6 in order to achieve an optimal surgical margin. Once the pulmonary lesion is localized, marking directly on the surface of the

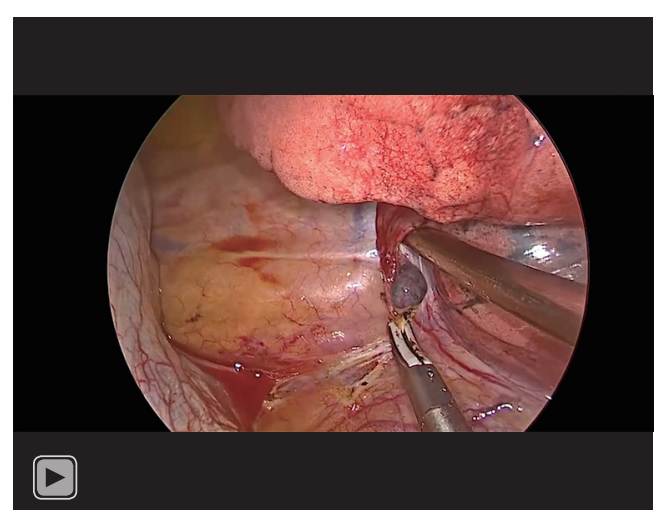

Video 1 Vein step. Description: Pulmonary ligament division. The common basal vein is dissected, encircled with a tape and divided using an angled vascular endostapler.

visceral pleura can be performed using electrocautery or sutures. This visual reference will be useful during the parenchyma division through the intersegmental plane. In case of peripheral millimetric and/or subsolid nodules such as ground glass opacities, transthoracic or bronchoscopic marking techniques can be helpful for detecting these kinds of untouchable lesions (10).

\section{Vein (Video 1)}

The pulmonary resection is initiated by sectioning the inferior pulmonary ligament. If there are any pulmonary ligament lymph nodes (Station 9) at this point, they should be removed. Once the inferior pulmonary vein is identified, both the main vein and segmental branches must be completely exposed clearing the surrounding tissues with a ultrasonic energy device. The most common anatomical pattern for the right inferior pulmonary vein is the division in the venous branch of the superior segment $\left(\mathrm{V}^{6}\right)$ and the common basal vein. After identification of $\mathrm{V}^{6}$ in the posterior side of the inferior pulmonary vein, the common basal vein is dissected, encircled with a tape and divided using an angled vascular endostapler inserted from the utility port in both uniportal and multiportal approaches.

Tips and tricks: a gentle retraction of the lower lobe toward the cranial side allows to expose properly the inferior pulmonary vein.

Caveats: possible anatomical variants must be always considered (Figure 1). These anomalous venous patterns should be suspected preoperatively by checking the HRCT scan. 

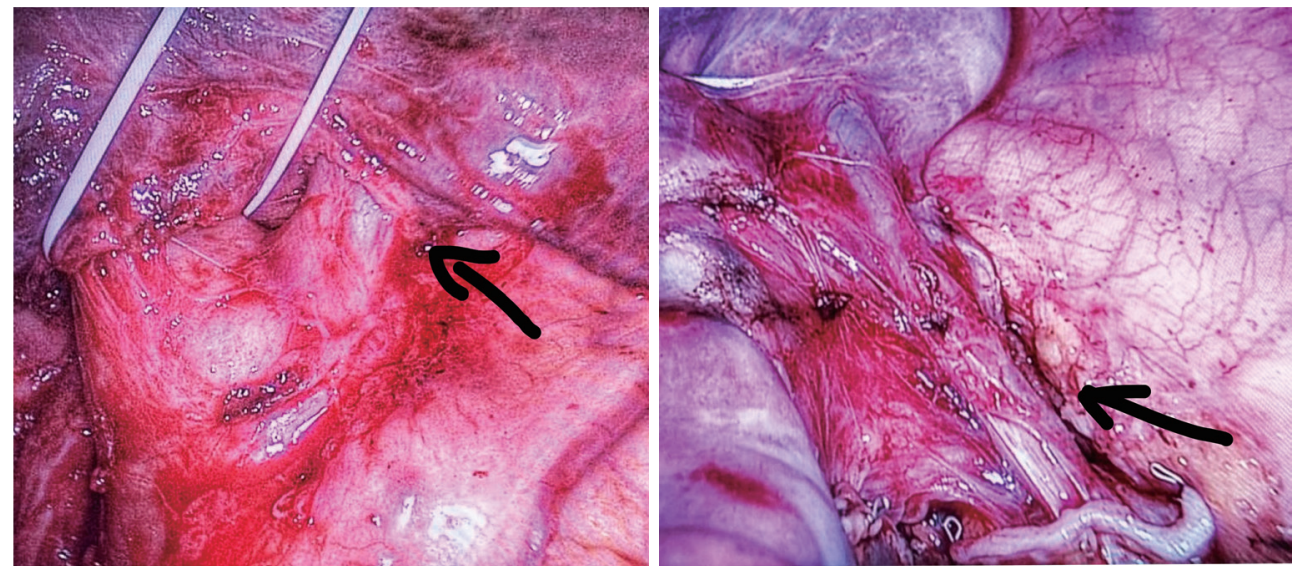

Figure 1 Middle lobe vein (black arrow) draining directly in the right inferior pulmonary vein.

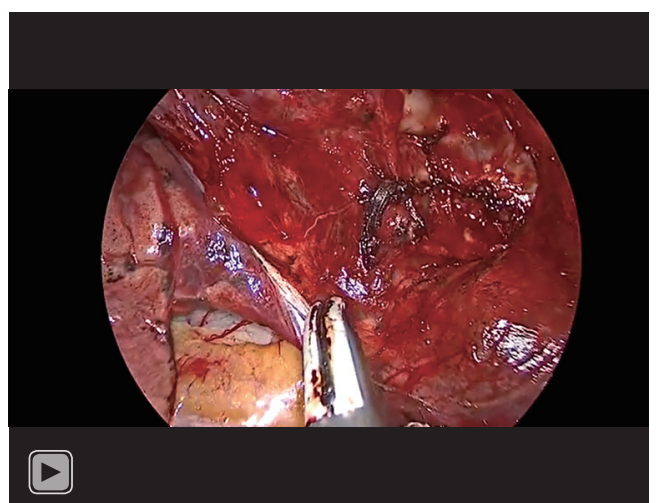

Video 2 Artery step. Description: Identification of the pulmonary artery in the fissure. A6 and the arterial trunk are exposed. The basal arterial trunk is dissected, passed with a dissecting forceps, encircled with a tape and finally stapled.

\section{Artery (Video 2)}

This step begins by locating the pulmonary artery at the junction of the minor and the oblique fissure. When the fissure is incomplete or inflammatory, this part could be more challenging and tedious. The inferior and superior pulmonary lobes are oppositely retracted in order to expose the interlobar plane. Once the pulmonary artery is identified, this should be completely dissected including the adventitial layer. Then, $\mathrm{A}^{6}$ and the basal trunk are clearly visualized. There are usually several lymph nodes surrounding the basal arterial trunk, specially between $\mathrm{A}^{6}$ and $\mathrm{A}^{9-10}$, and anterior to $\mathrm{A}^{7}$. All these lymph nodes need to be removed in order to fully expose the artery. Access to the basal trunk is facilitated by the division of the anterior portion of the oblique fissure between the middle lobe and the lower lobe. Stapling is preferable when this fissure is too thick, instead of bipolar or ultrasonic dissection. Once the anterior portion of the oblique fissure is opened, a dissecting forceps is introduced from the utility port passing the basal arterial trunk which is encircled with a tape and finally stapled.

Tips and tricks: the basal arterial trunk can be easily passed from the utility port using a curve-tip vascular stapler.

Caveats: the dissection of the fissure must be performed carefully so as to avoid troublesome oozing, parenchymal tears and postoperative air leaks.

\section{Bronchus and intersegmental plane division (Video 3)}

After cutting the basal arterial trunk, the surrounding peribronchial tissue is cleared circumferentially, including possible lymph nodes at this level. $\mathrm{B}^{6}$ must be also exposed. Both bronchial branches, basilar bronchus and $\mathrm{B}^{6}$, are clearly identify most of the times and bronchoscopic confirmation is not usually needed in this segmentectomy. Then, the basilar bronchus is passed with a dissecting forceps and referenced with an elastic tape. After clamping the basilar bronchus and ventilating the right lower lobe, the intersegmental plane between $S^{6}$ and $S^{7-10}$ is clearly visualized.

At this point, there are two possible alternatives.

(I) Bronchus-first: the basilar bronchus is sectioned using an endostapler. Right lower lobe retraction towards the cranial side can facilitate this maneuver. Then, the intersegmental plane is divided from the anterior to the posterior side along the inflation- 


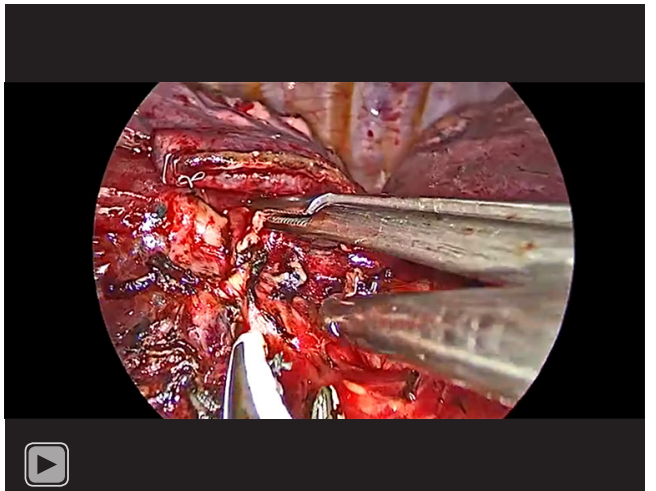

Video 3 Bronchus step. Description: the basilar bronchus is dissected and clamped. After ventilation, the intersegmental plane is clearly visualized. Once the intersegmental plane between S6 and S7-10 is completely divided, the basilar segments (S7-10) are just hanging from the basal bronchus which is sectioned.

deflation line. $V^{6}$ b (between $S^{6}$ and $S^{8}$ ) and $V^{6} c$ (between $S^{6}$ and $S^{10}$ ) run along the intersegmental plane and these venous branches must be respected.

(II) Parenchyma-first: a dissecting forceps is passed between the basal bronchus and $\mathrm{V}^{6}$, taping this new neo-fissure. This maneuver prevents cutting $\mathrm{V}^{6}$ accidentally, preserving the venous drainage of $\mathrm{S}^{6}$. The lung tissue is cut from anterior to posterior direction using several parenchymal reloads for endostapler. Once the intersegmental plane between $S^{6}$ and $S^{7-10}$ is completely divided, the basilar segments $\left(S^{7-10}\right)$ are just hanging from the basal bronchus which is sectioned.

During parenchyma stapling, the vascular and bronchial distal stumps should always be pushed away so they will remain included in the specimen side away from the stapler jaws. Once the basal pyramid is fully disconnected, the specimen is removed into an endobag. Possible air leaks must be tested insufflating the lung under the water.

Tips and tricks: a long clamp can be applied on the parenchyma, especially when the intersegmental tissue is too thick. This compression makes the stapler application easier.

Caveats: $\mathrm{V}^{6}$ must be always kept in mind during this step.

\section{Acknowledgments}

Funding: None.

\section{Footnote}

Provenance and Peer Review: This article was commissioned by the Guest Editor (Michel Gonzalez) for the series "VATS Segmentectomy" published in Fournal of Visualized Surgery. The article has undergone external peer review.

Peer Review File: Available at https://jovs.amegroups.com/ article/view/10.21037/jovs-21-32/prf

Conflicts of Interest: All authors have completed the ICMJE uniform disclosure form (available at https://jovs. amegroups.com/article/view/10.21037/jovs-21-32/coif). The series "VATS Segmentectomy" was commissioned by the editorial office without any funding or sponsorship. AO reports Collaboration with Astrazeneca and Corza; Coordinator of GEXT and Secretary of the Thoracic Surgery Area of Spanish Society of Pulmonology and Thoracic Surgery. The authors have no other conflicts of interest to declare.

Ethical Statement: The authors are accountable for all aspects of the work in ensuring that questions related to the accuracy or integrity of any part of the work are appropriately investigated and resolved. All procedures performed in studies involving human participants were in accordance with the ethical standards of the institutional and/or national research committee(s) and with the Helsinki Declaration (as revised in 2013). Written informed consent was obtained from the patient for publication of this manuscript and any accompanying images and videos.

Open Access Statement: This is an Open Access article distributed in accordance with the Creative Commons Attribution-NonCommercial-NoDerivs 4.0 International License (CC BY-NC-ND 4.0), which permits the noncommercial replication and distribution of the article with the strict proviso that no changes or edits are made and the original work is properly cited (including links to both the formal publication through the relevant DOI and the license). See: https://creativecommons.org/licenses/by-nc-nd/4.0/.

\section{References}

1. Berry MF. Role of segmentectomy for pulmonary metastases. Ann Cardiothorac Surg 2014;3:176-82.

2. Nelson DB, Tayob N, Mitchell KG, et al. Surgical margins 
and risk of local re-currence after wedge resection of colorectal pulmonary metastases. J Thorac Cardiovasc Surg 2019;157:1648-55.

3. Shiono S, Okumura T, Boku N, et al. Outcomes of segmentectomy and wedge resection for pulmonary metastases from colorectal cancer. Eur J Cardiothorac Surg 2017;51:504-10.

4. Bilgi Z, Swanson SJ. Current indications and outcomes for thoracoscopic seg-mentectomy for early stage lung cancer. J Thorac Dis 2019;11:S1662-9.

5. Leshnower BG, Miller DL, Fernandez FG, et al. Videoassisted thoracoscopic surgery segmentectomy: a safe and effective procedure. Ann Thorac Surg 2010;89:1571-6.

6. White A, Swanson SJ. Video-assisted thoracic surgery (VATS) segmentectomy: state of the art. Minerva Chir 2016;71:61-6.

doi: $10.21037 /$ jovs-21-32

Cite this article as: Obeso A, Galvez C, Rivo E, Quiroga J, Garcia Prim JM. Video-assisted thoracic surgery right lower lobe common basal segmentectomy (S7-S8-S9-S10). J Vis Surg 2021;7:48.
7. Nakamura K, Saji H, Nakajima R, et al. A phase III randomized trial of lobecto-my versus limited resection for small-sized peripheral non-small cell lung cancer (JCOG0802/WJOG4607L). Jpn J Clin Oncol 2010;40:271-4.

8. Nomori H, Okada M. Illustrated Anatomical Segmentectomy for Lung Cancer. Springer, 2012. DOI: 10.1007/978-4-431-54144-8_4.

9. $\mathrm{Hu} \mathrm{W}$, Zhang $\mathrm{K}$, Han X, et al. Three-dimensional computed tomography angi-ography and bronchography combined with three-dimensional printing for thoracoscopic pulmonary segmentectomy in stage IA non-small cell lung cancer. J Thorac Dis 2021;13:1187-95.

10. Obeso A, Abada H, Souilamas R. Hybrid Procedures for Pulmonary Nodule Re-section: The Beginning of a New Era. Arch Bronconeumol (Engl Ed) 2018;54:183-4. 